\title{
Use of obesity biomarkers in cardiovascular epidemiology
}

\author{
Tobias Pischon* \\ Department of Epidemiology, German Institute of Human Nutrition Potsdam-Rehbruecke, Nuthetal, Germany
}

\begin{abstract}
Obesity is an established risk factor for cardiovascular disease (CVD), yet, the underlying mechanisms are only poorly understood. The adipose tissue produces a variety of hormones and cytokines and thereby actively participates in a network of biomarkers that may be relevant for the development of CVD. Such obesity biomarkers have a great potential to better characterize the obesity phenotype that may be relevant for the risk of CVD beyond anthropometric parameters. They may be used to support mechanistic studies, to help identify individuals at risk for CVD, and to evaluate the effect of preventive measures. The present article discusses the role of some of the most promising obesity biomarkers in cardiovascular epidemiology, including inflammatory markers, adiponectin, resistin, and fetuin-A. Importantly, some of these markers have been related to cardiovascular risk even after accounting for anthropometric parameters. Further, the potential ability to manipulate blood levels of some of these biomarkers through medication, diet and lifestyle make them attractive markers for cardiovascular risk. However, many open questions remain - especially with regard to the causal role of the factors as well as with regard to the extent of improvement in CVD prediction by these markers - before measurement of these biomarkers may be recommended on a public health level.
\end{abstract}

Keywords: Epidemiology, cardiovascular disease, obesity, biomarkers, cohort study, prediction, diet, nutrition, lifestyle, primary prevention, reliability

\section{Introduction}

Obesity is a major risk factor for cardiovascular disease (CVD) [1]. However, although hypertension, dyslipidemia, insulin resistance, and type 2 diabetes as core components of the metabolic syndrome are probably key elements in the causal pathway from obesity to CVD the underlying mechanisms are only poorly understood. The adipose tissue produces a variety of hormones and cytokines and thereby actively participates in a network of biomarkers that may be relevant for the development of CVD [2]. The identification of obesity biomarkers related to CVD risk is important for scientific reasons to gain insight into pathophysiology, and for clinical and public health reasons because these biomarkers may improve the prediction of dis-

*Tobias Pischon, MD, MPH, Dept. of Epidemiology, German Institute of Human Nutrition Potsdam-Rehbruecke, Arthur-ScheunertAllee 114-116, 14558 Nuthetal, Germany. Tel.: +49 33200/88711; Fax: +49 33200/88721; E-mail: pischon@dife.de. ease incidence as well as prognosis and may also represent targets for interventions through means of diet, lifestyle or drug treatment. Visceral adipose tissue is metabolically more active and secretes more cytokines and hormones that are relevant for CVD compared with subcutaneous adipose tissue [2], yet BMI, which is currently used to define obesity, is only a crude measure of visceral fat mass. Waist circumference or waist-hip ratio, which show much closer correlations with the amount of visceral fat, may be better disease risk predictors [1]; however, even these anthropometric markers may be crude and imprecise and lead to underestimation of the disease risk associated with specific obesity patterns. Thus, identification of biomarkers which quantify metabolically active adipose tissue beyond anthropometric parameters is an alternative or complementary approach to define an 'obesity phenotype' that is relevant for CVD.

The present article discusses the role of obesity biomarkers in cardiovascular epidemiology. The article first presents a short description of the general 


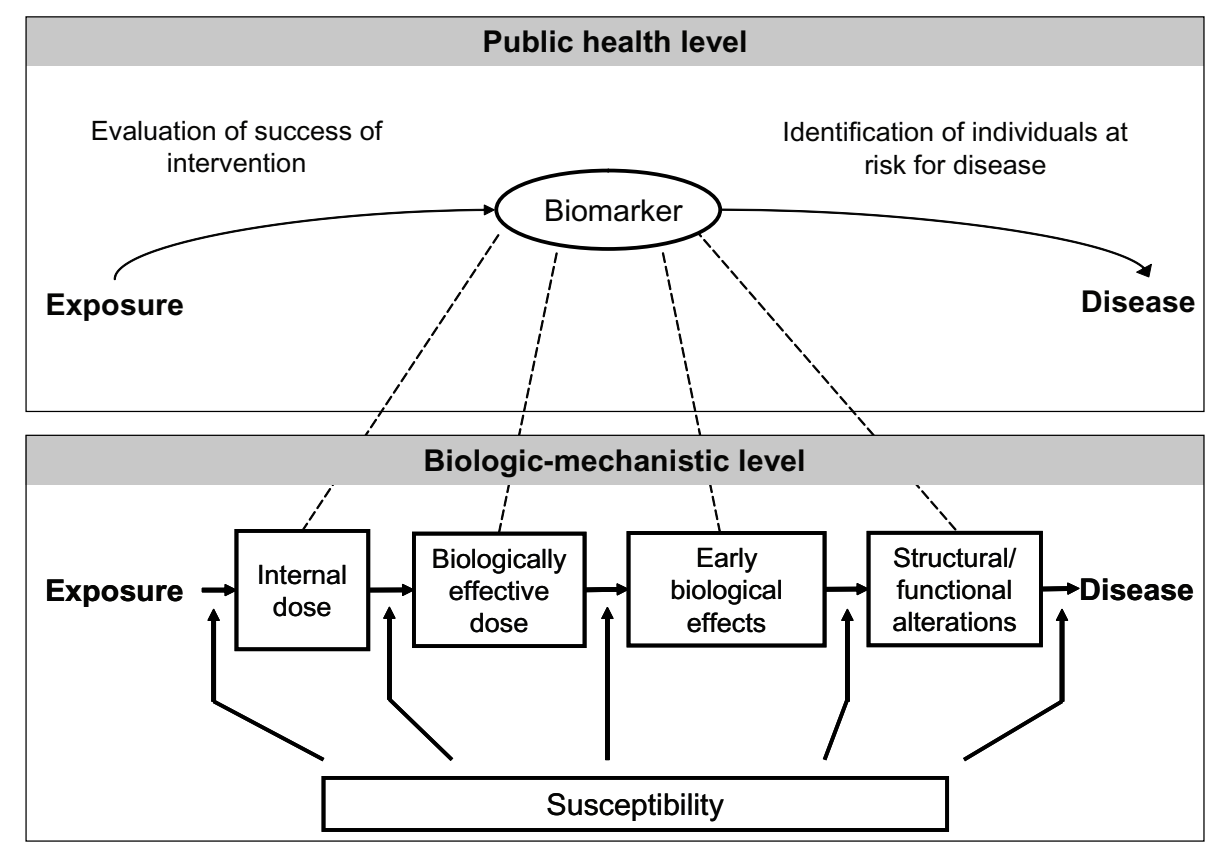

Fig. 1. Use of biomarkers in cardiovascular epidemiology. In cardiovascular epidemiology, biomarkers can be useful on a public health level as well as on a biologic-mechanistic level. On a public health level, biomarkers may be used to improve the identification of persons who are at risk for disease. In addition, they may be used as a proxy (or a surrogate) to evaluate the success of interventions that are aimed to reduce disease risk. On a biologic-mechanistic level, biomarkers may be useful to help clarify the relationship between exposure and disease and to give support for exposure-disease relationships. (Figure modified from [181]).

use of biomarkers in epidemiology, followed by a detailed description of some of the most promising obesity markers with regard to their association with CVD and their use as predictors of cardiovascular events, including inflammatory markers, adiponectin, resistin, and fetuin-A. The second part of the article briefly discusses methodological issues related to biomarker reliability, followed by an overview of the predictors of these biomarkers, with a special emphasis on diet and lifestyle factors. The article ends with a summary and conclusions about the potential use of obesity biomarkers for primary prevention of CVD.

\section{Use of biomarkers in epidemiology}

In epidemiological terms, a biomarker can be defined as "a cellular, biochemical, or molecular indicator of exposure; of biological, subclinical, or clinical effects; or of possible susceptibility" [3]. Biomarkers can be classified according to different schemes, for example, based on their function (e.g., markers of exposition, markers of effects, etc.), based on their biochemical or biological properties (e.g., proteins, metabolites, hormones, cytokines etc.), or based on the disease of inter- est (e.g., cardiovascular biomarkers, obesity biomarkers, etc.) [4,5]. Thus, a biomarker may reflect different concepts; for example, C-reactive protein (CRP) may be classified as a marker of inflammation, a marker of obesity, or a marker of CVD. Also, CRP can be used as a marker of exposure (e.g., CRP as a risk factor for CVD) but it can also be a marker of biological effects (e.g., measuring the effect of drug treatment). Biomarkers are primarily considered as substances that can be measured in the body; however, there are also more general definitions that consider as a biomarker any measurable parameter (e.g., an electrocardiogram recording, results of an imaging procedure, blood pressure levels, etc.) [6,7]. Biomarkers are useful in epidemiology not only because they may help clarify the relationship between exposure and disease (reflecting a mechanistic level) but because they may also help identify individuals at risk of disease and help quantify the effect of interventions that aim to reduce the risk of disease (reflecting a clinical or public health level, Fig. 1). The present article focuses on a group of biomarkers which are characterized by their association to obesity. This includes some of the so called "adipokines" (such as adiponectin or interleukin-6 [IL-6]), which are directly released from the adipose tissue (but may be 
released from other tissues as well), as well as some other biomarkers that are indirectly related to obesity (such as CRP).

\section{Obesity biomarkers and risk of CVD}

\subsection{Inflammatory markers}

The vast proportion of CVD develops on the basis of atherosclerosis, which was traditionally characterized primarily by the accumulation of lipids into the arterial walls. However, it is now well-established that inflammatory processes play an essential role in the initiation and progression of atherosclerosis as well as in the development of related complications, including the rupture of atherosclerotic plaques [8]. For example, the activation of endothelial cells by circulating lipoprotein particles and proinflammatory cytokines induces the expression of adhesion molecules, which promote adhesion of circulating leukocytes to the endothelium [9, 10]. This process promotes the diapedesis of leukocytes across the endothelial barrier into the tunica intima of the arterial wall, which leads to recruitment and accumulation of mononuclear phagocytes. Through different steps of development these mononuclear cells develop into macrophages and finally - by scavenger receptor mediated internalization of lipoprotein particles - into foam cells [10]. Foam cells may secrete proinflammatory cytokines and chemokines that further promote the inflammatory processes. Although it was already shown more than 30 years ago that circulating blood leukocyte concentration is related to risk of myocardial infarction, these inflammatory processes were traditionally considered to be local secondary phenomena, with hyper- or dyslipidemia as their primary cause $[2,11]$. However, it is now clear that systemic subclinical inflammatory processes often precede the development of cardiovascular events and are related to a higher cardiovascular risk. These subclinical inflammatory processes are promoted by secretion of proinflammatory cytokines by different tissues, including the adipose tissue [9].

TNF- $\alpha$ and IL- 6 are the major proinflammatory cytokines, which induce secretion of acute-phase proteins in the liver, including secretion of CRP. TNF- $\alpha$ and IL-6 are secreted by a variety of cell types, including - among others - monocytes, macrophages, and adipocytes $[12,13]$. The effects of TNF- $\alpha$ are mediated by two receptors, type 1 and type 2 (TNF-R 1 and TNF$\mathrm{R} 2$ ), which circulate in soluble forms (sTNF-R1 and
sTNF-R2, respectively), can be measured with greater sensitivity and reliability than can TNF- $\alpha$ itself, and reflect the activity of the TNF system $[14,15]$. Both TNF- $\alpha$ and IL-6 have been shown to impair intracellular insulin signaling, which may lead to insulin resistance $[16,17]$, and in humans, plasma levels of TNF- $\alpha$, the soluble TNF receptors, IL-6, and CRP are related to obesity and insulin resistance $[12,13]$. Further, there is evidence that these inflammatory markers may also contribute to the development of atherosclerosis and its complications $[10,18]$.

Of all inflammatory markers studied so far, CRP has been shown to be most consistently associated with risk of CVD, including most prominently CHD but also stroke [19-24]. CRP levels below $1.0 \mathrm{mg} / \mathrm{L}$ are considered to indicate low risk, CRP levels between 1.0 and $2.9 \mathrm{mg} / \mathrm{L}$ intermediate risk, and levels greater than or equal to $3.0 \mathrm{mg} / \mathrm{L}$ high risk. For example, in a combined analysis of men and women from the Nurses' Health Study and the Health Professionals Follow-up Study, people with CRP levels $\geqslant 3.0 \mathrm{mg} / \mathrm{L}$ had a 1.68 -fold higher risk to develop CHD compared to persons with CRP levels $<1.0 \mathrm{mg} / \mathrm{L}$. Importantly, measurement of CRP levels has also been shown to improve the prediction of cardiovascular events [25-27]. While knowledge of CRP levels in addition to other established risk factors of CVD probably does not substantially improve the discrimination between individuals who will develop cardiovascular events and those who will not, such knowledge is likely to improve the classification of persons into risk categories, and thus provide more accuracy in prediction. For example, in the Women's Health Study, the C-index (as a measure of discrimination) for the prediction of cardiovascular events based on the Framingham Risk Score (including age, total cholesterol [or LDL-cholesterol], HDL-cholesterol, systolic blood pressure, and smoking status) was 0.813 without CRP, and 0.815 with CRP, indicating only a small improvement in discrimination when CRP is added to traditional risk factors [25]. However, the predicted CVD risk categories changed substantially with the addition of CRP. For example, among women classified as having a 10 -year risk of CVD between $5 \%$ and $10 \%$ based on the model without CRP, $21.3 \%$ of women were reclassified with the addition of CRP as having either a lower or a higher risk. Importantly, the models that included CRP also estimated the actual risk of CVD more accurately than the model without CRP [25]. On a population level, it was estimated that approximately $33 \%$ of incident cases of myocardial infarction and $19 \%$ of incident stroke can be attributed to CRP levels $\geqslant 1.0 \mathrm{mg} / \mathrm{L}[20]$. 
Beside CHD and stroke, plasma CRP levels are also related to higher risks of other chronic diseases, including hypertension [28], peripheral arterial vascular disease [29], type 2 diabetes [30], and some types of cancer [31]. There is an ongoing debate as to whether CRP is a true risk factor or only a risk marker [32]. Animal studies have shown that CRP may accelerate the progression of atherosclerosis, arguing for a causal role of CRP [33]. Further, in persons with low LDLcholesterol levels $(<130 \mathrm{mg} / \mathrm{dL})$ and high CRP levels $(\geqslant 2.0 \mathrm{mg} / \mathrm{L})$ treatment with rosuvastatin (a hydroxymethylglutarylcoenzyme A reductase inhibitor) was associated with a reduction of CRP levels and a significantly reduced incidence of major cardiovascular events [34]. However, statins also lower LDLcholesterol levels; therefore, there is no proof that the risk reduction can solely be attributed to lowering of CRP levels [35]. In contrast to these trials, results from Mendelian randomization studies found that variations in the CRP gene that are related to meaningful variations in plasma levels of CRP are not associated with risk of CHD, arguing against a causal role of CRP in CVD development [36,37].

The role of other inflammatory markers in the development of CVD, and their use as risk factors or risk markers in epidemiology is less clear. While many inflammatory markers have been positively related to risk of CVD in some studies, these associations were often not replicated in other studies. The reasons for these inconsistencies are unclear and may be related to differences in study populations, length of follow-up, or degree of adjustment. For example, the soluble TNF receptors have been shown to be related to a higher risk of CHD in women, but these associations were attenuated and no longer significant after adjustment for traditional cardiovascular risk factors [19]. Other inflammatory markers, such as soluble adhesion molecules [38], IL-6 [39], or fibrinogen [40], have been found to be related to a higher risk of CVD even after multivariable adjustment; however, it is less clear to what extent such markers would improve the prediction of CVD, and their causal role is less established. For example, although a meta-analysis found fibrinogen levels related to a higher risk of CVD [40], genetic variants that are related to meaningful variations in fibrinogen levels were not related to risk of CVD [41], arguing against a causal role.

\subsection{Adiponectin}

Adiponectin (also called Acrp30, AdipoQ, apM1, and GBP28) is a 247-amino acid peptide hormone of $30 \mathrm{kDa}$ induced early in the differentiation of adipocytes that consists of an $\mathrm{N}$-terminal collagenous and a C-terminal globular domain, and that shares homology with subunits of complement factor C1q [42]. Through associations between the globular domains three adiponectin monomers form a trimer, and the trimers associate through the collagenous domains to form hexamers, which further assemble to multimers [43]. Contrary to other adipose-derived hormones, adiponectin circulates at relatively high concentrations in the blood stream, accounting for $0.05 \%$ of total serum proteins, and is inversely associated with obesity, insulin resistance, and type 2 diabetes. Animal studies suggest that administration of adiponectin improves insulin sensitivity and may have anti-atherogenic and anti-inflammatory properties [42, 43]. Adiponectin increases fatty acid oxidation and glucose uptake, reduces fatty acid synthesis, and decreases expression of molecules involved in gluconeogenesis in animal models. In vitro, adiponectin inhibits endothelial nuclear transcription factor NF- $\kappa \mathrm{B}$ signaling, which mediates the effects of pro-inflammatory cytokines, and it may also stimulate the production of nitric oxide in vascular endothelial cells and inhibit the expression of adhesion molecules and class A scavenger receptors as well as the proliferation and migration of human aortic smooth muscle cells $[42,43]$. Adiponectin may thus beneficially affect glucose and lipid metabolism, inflammation, endothelial function, as well as thrombogenesis, and it thereby may be crucial in several steps in the pathogenetic pathway from obesity to CVD. In fact, experimental in vivo studies have shown that supplementation of adiponectin (e.g., by treatment with recombinant adenoviruses or by transgenic overexpression) suppresses the development of atherosclerosis in animal models [43].

In humans, individuals with CHD or cerebrovascular disease have lower adiponectin levels than healthy controls [44-47]. This association is independent of traditional cardiovascular risk factors (including BMI), it was consistently seen in various ethnic populations [45-50], and it follows a "dose-response" relationship, with lower adiponectin levels in more severe forms of CHD [51-55]. Adiponectin is inversely associated with several cardiovascular risk factors, such as blood pressure and heart rate, as well as with plasma levels of glucose, insulin, triglycerides and inflammatory markers, and it is positively related to HDLcholesterol levels [56]. However, the causal role of adiponectin in the development of CVD and its use as a risk factor or risk marker for CVD remains con- 
troversial [57]. In the Health Professionals Follow-up Study, high plasma adiponectin levels were related to a significantly lower risk of CHD over a follow-up period of 6 years, independent of other cardiovascular risk factors [58]; a finding that was confirmed among diabetic patients in this cohort [59]. Further, low plasma adiponectin levels have been shown to predict the progression of coronary calcification in humans [60]. Results from other studies, however, provided inconsistent results, with some showing significant inverse associations between adiponectin and risk of CVD, whereas in other studies these relationships were not statistically significant after adjustment for other risk factors, especially after adjustment for HDL cholesterol levels and diabetes [61-68]; factors which may lie in the causal pathway, suggesting that the effect of adiponectin on CVD (if causal) may largely be explained by its effect on lipid or glucose metabolism.

Some studies also suggest that high adiponectin levels may be related to an increased risk of mortality among patients with CHD or heart failure, and possibly even among individuals without diagnosed CVD [6975]. These findings seem counterintuitive, given the beneficial effects of adiponectin on metabolism, on the cardiovascular system, and also on cancer development observed in animal studies [43,76]. Although adiponectin may increase energy expenditure and fatty acid oxidation, and may thereby lead to weight loss, it is currently unclear through which mechanisms higher adiponectin levels would causally increase the risk of death. As an alternative explanation, high adiponectin levels may be a marker for wasting processes in individuals with certain underlying diseases. In fact, adiponectin levels are increased in conditions related to wasting, including heart failure, liver cirrhosis, rheumatoid arthritis, inflammatory bowel disease, systemic lupus erythematosus, and old age $[70,77,78]$. Importantly, available studies that found a positive relationship between adiponectin levels and mortality were conducted among elderly individuals who are more likely to have underlying chronic diseases that may be related to wasting $[73,74]$. The overall picture that emerges based on these results resembles at least to some extent the complex associations that exist between BMI and mortality. Thus, although obesity a well-established risk factor for CVD [1], BMI is inversely related to risk of mortality among patients with heart failure; a phenomenon that has been described as "obesity paradox" [79] or "reverse epidemiology" [80]. The exact mechanisms of the "obesity paradox" are not entirely clear but may include cardiac cachexia and wasting in patients with heart failure, which is related to lower BMI and higher mortality [79]. Likewise, it was shown that the association of BMI with risk of death may depend on age or the presence or absence of underlying disease [81]. Similar effect modifications may also exist for the association of adiponectin with mortality, although the present studies do not allow definite conclusions about this issue. High adiponectin levels may also be a result of impaired renal clearance in vulnerable individuals, which in turn may be related to increased mortality, or they may reflect an attempt of the body of counter-regulation or compensation in certain severe chronic diseases [78].

In addition to the issues highlighted above, the effects of adiponectin may depend on its quaternary structure in plasma, or on its receptors. Adiponectin circulates in plasma as low, medium, and high molecular weight (HMW) forms, and it was suggested that HMW adiponectin may be more closely related to insulin sensitivity than other forms or the total amount of adiponectin [43]. In fact, a recent study suggested that HMW adiponectin is closer related to the incidence of type 2 diabetes than total adiponectin [82]; however, in the British Women's Heart and Health Study, HMW adiponectin was not significantly related to risk of CHD [83]. A number of adiponectin receptors has been identified, including AdipoR1, AdipoR2, T-cadherin, as well as calreticulin, and it was suggested that the metabolic effects of adiponectin may depend on the extent and the pattern of the expression of its receptors [43,84]. However, little information is available about the relevance of the adiponectin receptors for the development of CVD in humans.

In summary, although current evidence suggests a causal protective role of adiponectin in the development of CVD in humans it is premature to conclude about whether or not plasma adiponectin levels may improve the prediction of future cardiovascular events in humans.

\subsection{Resistin}

Resistin is an adipokine that was reported to be elevated in obese $\mathrm{C} 57 \mathrm{Bl} / 6 \mathrm{~J}$ mice on a high fat diet and suppressed by treatment with thiozolidinediones (TZDs) [85]. Resistin belongs to a family of resistinlike molecules (RELM), although the human genome only includes resistin and $\operatorname{RELM} \beta$ [86]. Treatment of wild type mice with recombinant resistin resulted in insulin resistance while administration of an antiresistin antibody increased insulin sensitivity in obese 
and insulin-resistant animals [85]. In contrast, in other experimental animal models of obesity (e.g. $d b / d b$ mice), plasma levels and adipose tissue mRNA expression of resistin were significantly lower compared to lean control mice [87-89]. Resistin and RELM $\beta$ specifically impair hepatic sensitivity to insulin, leading to increased glucose production, without affecting peripheral insulin sensitivity [90].

In humans, the role of resistin for obesity-related diseases is unclear. In contrast to mice, human resistin is expressed at lower levels in adipocytes but at higher levels in circulating blood monocytes [91, 92]. Furthermore, studies analyzing the relationship between adipose tissue resistin expression and insulin resistance, obesity, and type 2-diabetes yielded inconsistent results [91-93]. While some investigators [9496] found increased plasma resistin levels in obese or insulin-resistant subjects, others [97,98] found no such association. Interestingly, the amino acid sequences of resistin, $\operatorname{RELM} \alpha$, and $\operatorname{RELM} \beta$ are identical to the previously discovered proteins FIZZ3, FIZZ1, and FIZZ2, respectively, which are involved in inflammatory processes $[99,100]$. Studies also found that resistin promotes endothelial cell activation, including the promotion of endothelin-1 release and the up-regulation of adhesion molecules and cytokines [101,102]. These findings suggested that resistin may be directly or indirectly related to CVD. In fact, cross-sectional and casecontrol studies found higher plasma resistin levels in subjects with CHD when compared to controls [103, 104]. Thus, a case-control study found that resistin levels were significantly higher in women with CHD compared to controls, independent of traditional cardiovascular risk factors, such as hypertension, diabetes, smoking, and BMI [104]. However, the relationship was substantially attenuated and no longer significant after adjustment for CRP levels [104], which is in line with the hypothesis that resistin may be linked with CVD via inflammatory pathways. However, other studies found resistin levels related to coronary artery calcification independent of CRP levels [105], suggesting that inflammation may not fully account for this association. When studied prospectively, high plasma resistin levels have been associated with an increased risk of incident myocardial infarction independent of other established cardiovascular risk factors [106]. Interestingly, this association was attenuated after adjustment for CRP, but it remained statistically significant, suggesting that this association can only partly be explained by elevated CRP levels. In contrast to myocardial infarction, plasma resistin levels were not significantly related to risk of ischemic stroke in that study [106]. Since atherosclerosis is a major precursor of both cardiovascular endpoints it is unclear why resistin may be related to myocardial infarction but not to stroke; however, such differences in associations are also well-known for other established risk factors of atherosclerosis, including hypertension, smoking and cholesterol [20,107-109]. Thus it is conceivable that specific processes linked to resistin may be more important for $\mathrm{CHD}$, but less relevant for the development of cerebrovascular events. This notion is underlined by a number of studies which found no association of resistin levels with intima media thickness of carotid arteries [110-112]. These putative pathogenic differences between cerebrovascular and coronary events are supported by the fact that coronary atherosclerosis manifests earlier in life than cerebral atherosclerosis [113]. Clearly, more research is necessary to shed more light on the role of resistin as a cardiovascular biomarker.

\subsection{Fetuin-A}

Fetuin-A, also referred to as $\alpha 2$-Heremans-Schmid glycoprotein, is almost exclusively expressed and secreted by the liver, particularly under hepatic steatosis [114]. Nonalcoholic fatty liver disease (NAFLD), ranging from simple steatosis to more severe forms of non-alcoholic steatohepatitis (NASH), is present in a majority of patients with obesity, diabetes, or the metabolic syndrome, and it is increasingly common in the general population [115]. In fact, it was estimated that $60-70 \%$ of people with obesity have some form of NAFLD [115]. Recent evidence suggests that NAFLD adds independently of established cardiovascular risk factors to risk of atherosclerosis and CVD [116], and it was shown that the severity of NAFLD is related to the extent of atherosclerosis [117,118]. Fetuin-A is a natural inhibitor of the insulin-stimulated insulin receptor tyrosine kinase and was shown to induce insulin resistance in rodents [119-122]. Studies in humans have demonstrated that circulating fetuin-A levels are positively associated with fat accumulation in the liver, insulin resistance, and the metabolic syndrome [114, $123,124]$, and prospective cohort studies have shown that fetuin-A is positively associated with risk of type 2 diabetes mellitus [125,126]. Besides induction of insulin resistance, recent data suggest that fetuin-A is also involved in subclinical inflammation. Thus, circulating fetuin-A correlates positively with CRP levels in humans $[124,126]$. Further, fetuin-A was recently found to induce cytokine expression in human mono- 
cytes and to reduce the expression of adiponectin in animals [127]. Taken together, fetuin-A may thus represent a pathway linking fatty liver with cardiovascular events by inducing insulin resistance and inflammation. In fact, a recent study found plasma fetuin-A levels significantly associated with the risk of myocardial infarction and ischemic stroke, independently of traditional cardiovascular risk factors [128]. Interestingly, in that study, the association was significant even when adjusted for potentially intermediary variables, including history of diabetes, or plasma levels of glucose, triglycerides, $\gamma$-glutamyltransferase, adiponectin, or CRP, suggesting that at least some of the potential effects of fetuin-A on vascular function may not be mediated by these factors [128]. The association of fetuinA with cardiovascular risk was equally strong in most subgroups examined, although it was stronger in individuals with lower total cholesterol levels $(<200 \mathrm{mg} / \mathrm{L})$ compared to those with higher levels $(\geqslant 200 \mathrm{mg} / \mathrm{L})$, and it was somewhat stronger in women than in men. These preliminary data suggest that fetuin-A may be more relevant in individuals who are considered to have a lower cardiovascular risk as estimated based on traditional risk factors. Counter intuitively, however, low fetuin-A levels were found to be associated with increased cardiovascular mortality in patients with end-stage renal disease and renal replacement therapy [129]. The reasons for this apparent paradox are unclear but may be related to the fact that hemodialysis is known to reduce fetuin-A levels [130], indicating that the observed inverse association in this group of patients may reflect the renal replacement therapy. Further, studies suggest that fetuin-A may be an inhibitor of calcification [131]; therefore, increased vascular calcification in patients with renal disease who display low fetuin-A levels may be among the mechanisms for increased mortality. Other studies on the role of fetuin-A in vascular calcification have provided inconsistent results [132-134], and data from a more recent study including a larger number of patients with less severe impairment of renal function did not support the conclusion that low fetuin-A levels are associated with increased all-cause or cardiovascular mortality [135]. Altogether, these data indicate that the role of fetuin-A in CVD seems to be complex and modulated by various pathogenetic mechanisms such as calcification, inflammation, and insulin resistance. Therefore, more research is warranted to determine the role of fetuin-A in the pathophysiology of CVD before more definite conclusions can be drawn.
Table 1

Reliability of obesity biomarkers*

\begin{tabular}{lccc}
\hline Biomarker & $\begin{array}{c}\text { Time interval } \\
\text { (years) }\end{array}$ & $\begin{array}{c}\text { Intraclass correlation } \\
\text { coefficient }\end{array}$ & Reference \\
\hline sTNF-R1 & 4 & 0.81 & $(155)$ \\
sTNF-R2 & 4 & 0.78 & $(155)$ \\
IL-6 & 4 & 0.47 & $(155)$ \\
CRP & 4 & 0.67 & $(155)$ \\
Adiponectin & 1 & 0.85 & $(182)$ \\
Resistin & 1 & 0.70 & $(183)$ \\
\hline
\end{tabular}

*Reliability was expressed as the intraclass correlation coefficient, which was calculated as the ratio of the biomarker's between-person variance to the sum of its between-person and its within-person variance over the depicted time interval.

\section{Reliability of obesity biomarkers}

One key feature for the use of biomarkers in epidemiology is their reliability, which can be estimated from calculating the intraclass correlation coefficient as the ratio of the between-person variance divided by the sum of the between-person and the within-person variance over time of that specific biomarker $[136,137]$. The intraclass correlation coefficient (and, thus, the reliability) can range between 0 and 1 , with values close to 0 indicating poor reliability and values close to 1 indicating perfect reliability. Reliability will be high if the between person-variation is relatively high compared to the within-person variation. The within-person variation of most biomarkers is obviously time-dependent in that it will generally increase (and, thus, reliability will decrease) over longer time periods. For disease prediction it is generally of interest to study biomarkers that reflect long-term exposure and thus have a high reliability, since low reliability will attenuate the associations with biomarkers (e.g., with disease risk) toward the null.

Most of the obesity biomarkers discussed within this article have high reliability (Table 1). Surprisingly, even CRP - as an acute phase protein which concentrations increase sharply during acute infections - has a high reliability, although for disease prediction it is generally recommended to disregard CRP levels greater than $10 \mathrm{mg} / \mathrm{L}$ since such levels may indicate acute infections [21]. Taken together, these data support the use of these biomarkers in epidemiologic studies, although reliability maybe somewhat limited for IL-6.

\section{Predictors of obesity biomarkers}

\subsection{Obesity}

At first glance it may be surprising to look for predictors of obesity biomarkers, since obesity should ob- 
Table 2

Correlation of obesity biomarkers with BMI in population-based studies*

\begin{tabular}{lcc}
\hline Biomarker & Correlation coefficient & Reference \\
\hline sTNF-R1 & 0.20 & $(19)$ \\
sTNF-R2 & 0.20 & $(19)$ \\
IL-6 & 0.26 & $(19)$ \\
CRP & 0.40 & $(19)$ \\
Adiponectin & -0.27 & $(58)$ \\
Resistin & 0.02 & $(106)$ \\
Fetuin-A & 0.06 & $(128)$ \\
Leptin & 0.65 & $(175)$ \\
\hline
\end{tabular}

*Data for sTNF-R1, sTNF-R2, IL-6, CRP, and leptin are from combined analyses of women from the Nurses' Health Study' and men from the Health Professionals Follow-up Study. Data for adiponectin are from analyses of men from the Health Professionals Follow-up Study. Data for resistin and fetuin-A are from combined analyses of men and women from the European Prospective Investigation into Cancer and Nutrition-Potsdam study.

viously be the main determinant of these biomarkers. However, that being said, the question is, what is obesity? Or, more precisely, how is obesity defined? Practically speaking the answer is straightforward. Currently, obesity is defined as a BMI $\geqslant 30.0 \mathrm{~kg} / \mathrm{m}^{2}$ [138]. However, with the exception of leptin, the correlation of BMI with most obesity biomarkers is at best only moderate (Table 2). In other words, BMI explains only a small proportion of the variance (up to $16 \%$ ) of most of the biomarkers discussed here. One may argue that the metabolic activity of different types of adipose tissue may vary; for example, it is well known that visceral adipose tissue is metabolically more active than subcutaneous adipose tissue [139]. In line with these differences, within the past years it became clear that the distribution of body fat is another key determinant of disease; thus, the measurement of waist circumference (and, although less popular, hip circumference and calculation of the waist to hip ratio) was suggested to more appropriately assess the risk of disease than BMI, and cut-off points for waist circumference of $102 \mathrm{~cm}$ in men and $88 \mathrm{~cm}$ in women have been suggested to define abdominal obesity [138]. However, even these anthropometric measures may be crude and include substantial measurement error to quantify the relevant obesity trait of interest. Thus, identification of biomarkers which quantitate metabolically active adipose may be the best way to define an 'obesity phenotype' that is relevant for chronic disease risk. The question then is: what are the determinants of that obesity phenotype, i.e., what are the predictors of these biomarkers beyond BMI?

\subsection{Genetic factors}

Genetic variation in biomarker levels may be caused directly by variants within genes that encode these biomarkers or indirectly via variants within genes that encode factors on a biomarker related pathway. Consequently, a large variety of genetic variants have been proposed to be related to obesity biomarkers, and a detailed description of these variants is beyond the scope of this review but can be found elsewhere [37,140]. For CRP and adiponectin, a number of variants within the CRP and the adiponectin gene have been shown to be related to blood CRP and adiponectin levels, although most of these SNPs have not been shown to be related to risk of CVD [36,37,140-143]. Recently, a few SNPs in the resistin gene have been identified to be related to resistin levels and to glucose levels [144], but in general, the relevance of SNPs in the resistin gene for the risk of CVD is unclear. Similarly, the role of SNPs in the IL-6 gene and the fetuin-A gene for variations in biomarker levels are currently unclear [145].

Besides variants in the genes that encode the biomarker, there is interest as to whether variants that affect the degree of adiposity (as measured by BMI) are also related to obesity biomarkers [146]. For example, recently, it was shown that variation at the fatmass and obesity-associated (FTO) gene locus - a gene locus that had been reported to be associated with increased body fat [147-149] - was also related to variations in blood CRP concentrations [150]. Interestingly, when further adjusted for BMI or waist circumference, the FTO SNP remained significantly related with CRP concentrations, suggesting that differences in BMI or waist circumference may not account for this association [150]. One may speculate whether adipose tissue sites that are more sensitive to infiltration of immune cells might be expanded preferentially in carriers of the variant FTO allele; however, as with any genetic study, these findings need confirmation before conclusions can be drawn.

Overall, most of the genetic variants studied so far explained only very small proportions in the variation of biomarker levels, and many association studies provided inconsistent results. For example, although the association was statistically significant, variation in the FTO gene explained less than $1 \%$ of variation in plasma CRP levels [150].

\subsection{Drugs}

A number of drugs have been reported to affect the plasma levels of the obesity biomarkers discussed herein. Thus, cyclooxygenase inhibitors, platelet aggregation inhibitors, lipid lowering agents, $\beta$-adrenoreceptor antagonists and antioxidants (vitamin E), some an- 
giotensin converting enzyme (ACE) inhibitors and angiotensin receptor blockers (ARBs), as well as some thiazolidinediones have all been shown to reduce serum levels of CRP [151]. The effect is best established for the hydroxymethylglutarylcoenzyme A reductase inhibitor (statins) where the CRP-lowering effect is more pronounced than their lipid lowering effect [34,151]. Similarly, the thiazolidinediones, which are used clinically to treat patients with type 2 diabetes, are among the most established modulators of plasma adiponectin levels [43]. They activate the peroxisome proliferatoractivated receptor $\gamma$ (PPAR- $\gamma$ ), upregulate the production of adiponectin and increase its plasma concentrations [43]. Currently, it is less clear which drugs affect circulating levels of resistin and fetuin-A

\subsection{Dietary and lifestyle factors}

Studying the association of dietary and lifestyle factors with circulating biomarker levels is of particular importance because the identification of dietary or lifestyle determinants may offer opportunities for the modification of adverse biomarker profiles on a population level using relatively easy measures, especially when compared with other, more expensive interventions, such as drug treatment. Among dietary factors, the effect of intake of different types of fatty acids on the development of CVD has been of considerable interest [152]. Thus, it is well established that intake of polyunsaturated fatty acids (PUFAs) favorably affects CVD, while intake of trans fatty acids increases the risk; however, the underlying mechanisms for these observations are only poorly understood and can only partly be explained by changes in blood lipid levels [152]. Intake of PUFAs has long been hypothesized to affect inflammation in humans, because these fatty acids cannot be synthesized de novo by human metabolism (although they can be modified and elongated) but are required for the synthesis of eicosanoids (including thromboxanes, prostaglandins, and leukotriens), which are involved in inflammatory processes [153]. Both $n-3$ and $n-6$ PUFAs are substrates for human eicosanoid production, and they share the same enzymes for the synthesis of prostaglandins and leukotrienes. Eicosanoids derived from $n-3$ fatty acids have fewer inflammatory properties than those derived from $n-6$ fatty acids, and it was thus proposed that the ratio of $n-3$ to $n-6$ fatty acid intake may be crucial to inflammatory processes [154]. It was shown that the $n-3$ fatty acids eicosapentaenoic acid (EPA) and docosahexaenoic acid (DHA) were in fact inversely related to plasma levels of sTNF-R1 and
sTNF-R2 and somewhat less so for CRP [155]. Interestingly, though, upon further analyses this association was stronger among individuals with high intake of $n-6$ fatty acids as compared to those with lower $n-6$ intake, suggesting that the combination of both types of fatty acids is associated with the lowest levels of inflammation [155], which is in contrast to the customary assumption that high intake of $n-6$ fatty acids antagonizes the anti-inflammatory effects of $n-3$ fatty acids. In contrast to these presumably beneficial effects of $n-3$ and $n-6$ fatty acids, it was shown that intake of trans fatty acids is positively associated with markers of systemic inflammation [156]. Thus, the modulation of inflammatory cytokines may be among the possible mechanism for the observed effects of fatty acid intake on CVD.

Alcohol consumption is another dietary factor that has received substantial attention with regard to its effect on CVD risk, as moderate alcohol consumption is known to be associated with a decreased risk of CVD [157]. It was estimated that half of this benefit may be explained through beneficial effects on lipids [158,159]. Interestingly, several studies have shown that moderate alcohol consumption is also related to lower inflammatory marker levels [160-162] and to higher levels of adiponectin [163,164]. These associations have largely been confirmed in experimental studies [165-169], suggesting that they may partly account for the association of moderate alcohol consumption with lower CVD risk [159].

Studies also suggest that the quality and quantity of carbohydrate intake may be related to obesity markers and to cardiovascular risk. For example, it was shown that a carbohydrate-rich diet with a high glycemic load is associated with lower adiponectin concentrations [163], higher levels of CRP [170], and with a higher risk of CHD [171].

Among lifestyle factors, physical activity has been identified as a key measure to reduce the risk of CVD [172]. Several observational and intervention studies have shown that physical activity is related to lower circulating inflammatory marker levels and to higher adiponectin levels [173-176]. However, it is unclear to what extent this association is accounted for by differences in body weight or body fat mass between individuals who are active and those who are inactive. For example, in a randomized controlled trial, Esposito et al. [174] found in obese women that an intervention consisting of a reduction in energy intake, adherence to an AHA recommended Mediterranean diet [177], and an increase in physical activity compared to a con- 
trol group over a 2-year period reduced mean CRP and IL-6 levels by $0.8 \mathrm{mg} / \mathrm{L}$ and $1.1 \mathrm{pg} / \mathrm{mL}$, respectively, while adiponectin levels increased by $2.2 \mu \mathrm{g} / \mathrm{mL}$. However, within that period, mean BMI levels decreased by $4 \mathrm{~kg} / \mathrm{m}^{2}$, and it is therefore unclear whether changes in biomarker levels were accounted for by changes in BMI, or whether the intervention contributed to the changes in biomarker levels beyond its effects on BMI. In a combined analysis of the Health Professionals Follow-up Study and the Nurses' Health Study it was shown that after further adjustment for BMI and leptin levels, as a surrogate for fat mass, the inverse association of physical activity with systemic inflammation was no longer significant, suggesting that the association can partially be explained by a lower degree of obesity in physically active subjects [175].

\section{Summary and conclusions}

During the past years, a number of obesity biomarkers has been identified, which encompass a relatively heterogeneous group of substances, some of which are directly secreted by the adipose tissue (the "adipokines") and some through indirect pathways related to the degree of adiposity. These findings support the view that the adipose tissue as an endocrine organ is involved in a hormonal network that may affect several different functions in the body. As more and more adipose-tissue-derived cytokines and hormones are being discovered, the complexity of the endocrine network of which these mediators are a part becomes more and more apparent. Regarded initially as markers mainly related to weight regulation and insulin resistance, it has become clear that several obesity hormones may be involved in a variety of functions and diseases, including cardiovascular disease, diabetes, and inflammatory diseases.

Biomarkers may be used in epidemiology on a mechanistic level to help clarify the relationship between exposure and disease but also on a public health level to help identify individuals at risk for disease. Many observational studies have shown that CRP levels are related to risk of CVD, independent of traditional risk factors, which is in line with the hypothesis that systemic inflammation causally contributes to the development of CVD. The evidence, however, is less clear for other inflammatory markers since observational studies provided somewhat inconsistent results. Adiponectin has been shown to be inversely related to the incidence of CHD, but in many studies this association was at- tenuated and no longer significant after adjustment for other risk factors, particularly after adjustment for circulating HDL cholesterol levels and the presence of diabetes. Since adiponectin is likely to be involved in the regulation of lipid and glucose metabolism, these findings suggest that most of the effect of adiponectin on cardiovascular risk (if causal) may be mediated by its effects on lipid or glucose metabolism. Based on animal studies, resistin was initially proposed to be involved in the development of insulin resistance, but recent results suggest that in humans it may be closer related to inflammatory processes and potentially to the development of CHD. Fetuin-A was discovered as a rather specific marker of fat accumulation in the liver that is also related to risk of type 2 diabetes and CVD; however, its role in the development of CVD needs to be established. What is noteworthy is that at least some of the obesity biomarkers discussed herein are related to risk of CVD even after adjusting for anthropometric parameters, such as BMI and waist circumference, suggesting that these biomarkers may be used to better define the obesity phenotype that is relevant for cardiovascular risk.

With regard to improving the identification of individuals at risk for CVD, many open questions remain. One of the foremost questions is how to adequately evaluate whether or not a marker improves the prediction of CVD [178]. Traditionally, prediction was evaluated using the c-statistic (which is a measure of discrimination that is analogous to the area under the receiver operating characteristics curve and - assuming a prospective setting - provides the probability that a prediction model assigns a higher risk to those who develop disease compared to those who do not) or the c-index (which is analogous to the c-statistic for censored data) [179]. However, the c-statistic is very insensitive to the addition of variables to a regression model even when they are established risk factors. As such, additional parameters have been proposed to assess whether a biomarker may improve the prediction of disease [178]. The majority of obesity biomarkers provide probably only little increment in the c-statistic when added to traditional cardiovascular risk factors to predict CVD risk, as it is the case for most other markers. However, despite little changes in discrimination the addition of biomarkers may improve the classification of persons into risk categories, as has been shown for CRP [25]. Clearly, more research is necessary to assess to what extent these biomarkers may improve the prediction of CVD.

If biomarkers are identified as being causally involved in the development of CVD then important ques- 


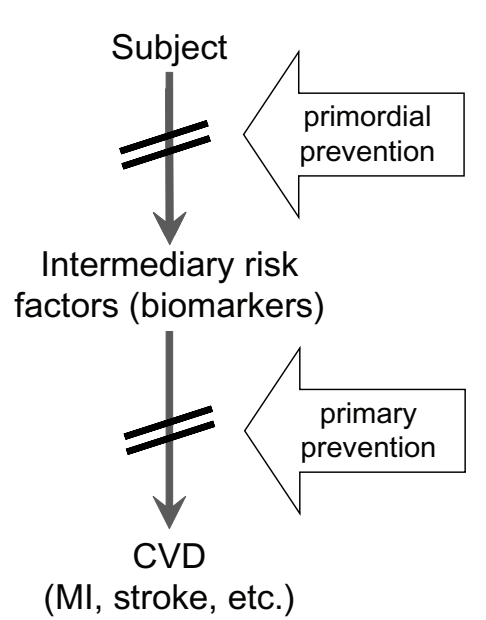

\section{Preventive factors}

Diet/Nutrition

- $\uparrow$ polyunsaturated fatty

acids

- $\uparrow$ omega 3-fatty acids

- $\uparrow$ fiber

- $\downarrow$ saturated fatty acids

- $\downarrow$ trans fatty acids

- $\downarrow$ processed carbs

- $\downarrow$ body weight

Lifestyle

- abstinence from smoking

- $\uparrow$ physical activity

- Moderate alcohol consumption

Fig. 2. Relevance of cardiovascular biomarkers in the prevention of cardiovascular diseases. Primary prevention aims to avoid or delay the occurrence of disease by recommending preventive factors. More specifically, primary prevention is intended to prevent disease by detecting and treating (intermediary) risk factors [180]. Primordial prevention (also called "health promotion") aims to avoid or delay the occurrence of (intermediary) risk factors [180]. Biomarkers therefore form an integral part as intermediary risk factors in the concept of primary and primordial prevention.

tions are whether and how the levels of these biomarkers can be modified to reduce cardiovascular risk. For many of the biomarkers discussed herein it was shown that their blood levels are determined not only by the degree of adiposity but also by other dietary and lifestyle factors. Such findings pave the way for further improving measures of primary and primordial prevention (Fig. 2). Identification of intermediary biomarkers may support primary prevention in at least two ways. First, biomarkers may be used to better identify persons at risk for disease who are then selected for measures of prevention. This refers to the more specific definition of primary prevention that is intended to prevent disease by detecting and treating (intermediary) risk factors [180]. Second, measurement of intermediary biomarkers offers the possibility to evaluate whether the application of preventive measures beneficially affect these biomarkers as surrogate markers of disease endpoint. Further, measures of prevention may be used to avoid the occurrence of (intermediary) risk factors, a concept which has been referred to as primordial prevention or health promotion [180].

In conclusion, obesity biomarkers hold promises to better characterize the obesity phenotype that may be relevant for the risk of CVD. Further, these biomarkers may be used to help identify individuals at risk for CVD, and they may be used in primary prevention to evaluate the effect of preventive measures. However, many open questions remain - especially with regard to the causal role of the factors as well as with regard to the extent of improvement in CVD prediction by these markers - before measurement of these biomarkers may be recommended on a public health level.

\section{Acknowledgments}

I thank Prof. Heiner Boeing for critical comments to the manuscript.

\section{References}

[1] P. Poirier, T.D. Giles, G.A. Bray et al., Obesity and cardiovascular disease: pathophysiology, evaluation, and effect of weight loss: an update of the 1997 American Heart Association Scientific Statement on Obesity and Heart Disease from the Obesity Committee of the Council on Nutrition, Physical Activity, and Metabolism, Circulation 113(6) (2006), 898-918.

[2] A.H. Berg and P.E. Scherer, Adipose tissue, inflammation, and cardiovascular disease, Circ Res 96(9) (2005), 939-949.

[3] M. Porta, A Dictionary of Epidemiology, (5 ed.), New York: Oxford University Press, 2008.

[4] P.A. Schulte and M. Waters, Using molecular epidemiology in assessing exposure for risk assessment, Ann N Y Acad Sci 895 (1999), 101-111.

[5] B.S. Hulka and B.H. Margolin, Methodological issues in epidemiologic studies using biologic markers, Am J Epidemiol 135(2) (1992), 200-209.

[6] R.S. Vasan, Biomarkers of cardiovascular disease: molecular basis and practical considerations, Circulation 113(19) (2006), 2335-2362.

[7] Biomarkers Definitions Working Group. Biomarkers and surrogate endpoints: preferred definitions and conceptual framework, Clin Pharmacol Ther 69(3) (2001), 89-95. 
[8] R. Ross, Atherosclerosis-an inflammatory disease, $N$ Engl J Med 340(2) (1999), 115-126.

[9] G.K. Hansson, Inflammation, atherosclerosis, and coronary artery disease, $N$ Engl J Med 352(16) (2005), 1685-1695.

[10] P. Libby, Inflammation in atherosclerosis, Nature 420(6917) (2002), 868-874.

[11] G.D. Friedman, A.L. Klatsky and A.B. Siegelaub, The leukocyte count as a predictor of myocardial infarction, $N$ Engl J Med 290(23) (1974), 1275-1278.

[12] G.S. Hotamisligil, The role of TNFalpha and TNF receptors in obesity and insulin resistance, J Intern Med 245(6) (1999), 621-625.

[13] P.A. Kern, S. Ranganathan, C. Li, L. Wood and G. Ranganathan, Adipose tissue tumor necrosis factor and interleukin-6 expression in human obesity and insulin resistance, Am J Physiol Endocrinol Metab 280(5) (2001), E745E751.

[14] A. Diez-Ruiz, G.P. Tilz, R. Zangerle, G. Baier-Bitterlich, H. Wachter and D. Fuchs, Soluble receptors for tumour necrosis factor in clinical laboratory diagnosis, Eur J Haematol 54(1) (1995), 1-8.

[15] D. Aderka, The potential biological and clinical significance of the soluble tumor necrosis factor receptors, Cytokine Growth Factor Rev 7(3) (1996), 231-240.

[16] G.S. Hotamisligil, Molecular mechanisms of insulin resistance and the role of the adipocyte, Int J Obes Relat Metab Disord 24(Suppl 4) (2000), S23-S27.

[17] V. Rotter, I. Nagev and U. Smith, Interleukin-6 (IL-6) Reduces Gene and Protein Expression of IRS-1 and GLUT4 and Is Overexpressed in Human Fat Cells from Insulin-Resistant Subjects, Diabetes 51(Suppl 2) (2002), A303.

[18] G.J. Blake and P.M. Ridker, Inflammatory bio-markers and cardiovascular risk prediction, J Intern Med 252(4) (2002), 283-294.

[19] J.K. Pai, T. Pischon, J. Ma et al., Inflammatory Markers and the Risk of Coronary Heart Disease in Men and Women, $N$ Engl J Med 351(25) (2004), 2599-2610.

[20] T. Pischon, M. Mohlig, K. Hoffmann et al., Comparison of relative and attributable risk of myocardial infarction and stroke according to C-reactive protein and low-density lipoprotein cholesterol levels, Eur J Epidemiol 22(7) (2007), 429-438.

[21] T.A. Pearson, G.A. Mensah, R.W. Alexander et al., Markers of inflammation and cardiovascular disease: application to clinical and public health practice: A statement for healthcare professionals from the Centers for Disease Control and Prevention and the American Heart Association, Circulation 107(3) (2003), 499-511.

[22] M. Di Napoli, M. Schwaninger, R. Cappelli et al., Evaluation of C-reactive protein measurement for assessing the risk and prognosis in ischemic stroke: a statement for health care professionals from the CRP Pooling Project members, Stroke 36(6) (2005), 1316-1329.

[23] P.M. Ridker, C.H. Hennekens, J.E. Buring and N. Rifai, Creactive protein and other markers of inflammation in the prediction of cardiovascular disease in women, $N$ Engl J Med 342(12) (2000), 836-843.

[24] J. Danesh, J.G. Wheeler, G.M. Hirschfield et al., C-reactive protein and other circulating markers of inflammation in the prediction of coronary heart disease, $N$ Engl J Med 350(14) (2004), 1387-1397.

[25] N.R. Cook, J.E. Buring and P.M Ridker, The effect of including C-reactive protein in cardiovascular risk prediction models for women, Ann Intern Med 145(1) (2006), 21-29.
[26] P.M. Ridker, J.E. Buring, N. Rifai and N.R. Cook, Development and validation of improved algorithms for the assessment of global cardiovascular risk in women: the Reynolds Risk Score, Jama 297(6) (2007), 611-619.

[27] P.M. Ridker, N.P. Paynter, N. Rifai, J.M. Gaziano and N.R. Cook, C-reactive protein and parental history improve global cardiovascular risk prediction: the Reynolds Risk Score for men, Circulation 118(22) (2008), 2243-2251, 4p following 51.

[28] H.D. Sesso, J.E. Buring, N. Rifai, G.J. Blake, J.M. Gaziano and P.M. Ridker, C-reactive protein and the risk of developing hypertension, Jama 290(22) (2003), 2945-2951.

[29] P.M. Ridker, M. Cushman, M.J. Stampfer, R.P. Tracy and C.H. Hennekens, Plasma concentration of C-reactive protein and risk of developing peripheral vascular disease, Circulation 97(5) (1998), 425-428.

[30] B. Thorand, H. Lowel, A. Schneider et al., C-Reactive Protein as a Predictor for Incident Diabetes Mellitus Among Middleaged Men: Results From the MONICA Augsburg Cohort Study, 1984-1998, Arch Intern Med 163(1) (2003), 93-99.

[31] K. Heikkila, S. Ebrahim and D.A. Lawlor, A systematic review of the association between circulating concentrations of $\mathrm{C}$ reactive protein and cancer, $J$ Epidemiol Community Health 61(9) (2007), 824-833.

[32] H. Schunkert and N.J. Samani, Elevated C-reactive protein in atherosclerosis - chicken or egg? $N$ Engl J Med 359(18) (2008), 1953-1955.

[33] A. Paul, K.W. Ko, L. Li et al., C-reactive protein accelerates the progression of atherosclerosis in apolipoprotein Edeficient mice, Circulation 109(5) (2004), 647-655.

[34] P.M. Ridker, E. Danielson, F.A. Fonseca et al., Rosuvastatin to prevent vascular events in men and women with elevated C-reactive protein, N Engl J Med 359(21) (2008), 21952207

[35] M.A. Hlatky, Expanding the orbit of primary preventionmoving beyond JUPITER, N Engl J Med 359(21) (2008), 2280-2282.

[36] J.K. Pai, K.J. Mukamal, K.M. Rexrode and E.B. Rimm, CReactive Protein (CRP) Gene Polymorphisms, CRP Levels, and Risk of Incident Coronary Heart Disease in Two Nested Case-Control Studies, PLoS ONE 3(1) (2008), e1395.

[37] J. Zacho, A. Tybjaerg-Hansen, J.S. Jensen, P. Grande, H. Sillesen and B.G. Nordestgaard, Genetically elevated Creactive protein and ischemic vascular disease, $N$ Engl J Med 359(18) (2008), 1897-1908.

[38] I. Shai, T. Pischon, F.B. Hu, A. Ascherio, N. Rifai and E.B. Rimm, Soluble intercellular adhesion molecules, soluble vascular cell adhesion molecules, and risk of coronary heart disease, Obesity (Silver Spring) 14(11) (2006), 2099-2106.

[39] J. Danesh, S. Kaptoge, A.G. Mann et al., Long-term interleukin-6 levels and subsequent risk of coronary heart disease: two new prospective studies and a systematic review, PLoS Med 5(4) (2008), e78.

[40] J. Danesh, S. Lewington, S.G. Thompson et al., Plasma fibrinogen level and the risk of major cardiovascular diseases and nonvascular mortality: an individual participant metaanalysis, Jama 294(14) (2005), 1799-1809.

[41] B. Keavney, J. Danesh, S. Parish et al., Fibrinogen and coronary heart disease: test of causality by 'Mendelian randomization', Int J Epidemiol 35(4) (2006), 935-943.

[42] M.E. Trujillo and P.E. Scherer, Adiponectin - journey from an adipocyte secretory protein to biomarker of the metabolic syndrome, J Intern Med 257(2) (2005), 167-175. 
[43] J.P. Whitehead, A.A. Richards, I.J. Hickman, G.A. Macdonald and J.B. Prins, Adiponectin - a key adipokine in the metabolic syndrome, Diabetes Obes Metab 8(3) (2006), 264-280.

[44] K. Hotta, T. Funahashi, Y. Arita et al., Plasma concentrations of a novel, adipose-specific protein, adiponectin, in type 2 diabetic patients, Arterioscler Thromb Vasc Biol 20(6) (2000), 1595-1599.

[45] M. Kumada, S. Kihara, S. Sumitsuji et al., Association of hypoadiponectinemia with coronary artery disease in men, Arterioscler Thromb Vasc Biol 23(1) (2003), 85-89.

[46] S. Kojima, T. Funahashi, T. Sakamoto et al., The variation of plasma concentrations of a novel, adipocyte derived protein, adiponectin, in patients with acute myocardial infarction, Heart 89(6) (2003), 667.

[47] J. Lo, S.E. Dolan, J.R. Kanter et al., Effects of obesity, body composition, and adiponectin on carotid intima-media thickness in healthy women, J Clin Endocrinol Metab 91(5) (2006), 1677-1682.

[48] D. Rothenbacher, H. Brenner, W. Marz and W. Koenig, Adiponectin, risk of coronary heart disease and correlations with cardiovascular risk markers, Eur Heart J 26(16) (2005), 1640-1646.

[49] G. Lu, A. Chiem, E. Anuurad et al., Adiponectin levels are associated with coronary artery disease across Caucasian and African-American ethnicity, Transl Res 149(6) (2007), 317323.

[50] M.P. Chen, J.C. Tsai, F.M. Chung et al., Hypoadiponectinemia is associated with ischemic cerebrovascular disease, $\mathrm{Ar}$ terioscler Thromb Vasc Biol 25(4) (2005), 821-826.

[51] Y. Nakamura, K. Shimada, D. Fukuda et al., Implications of plasma concentrations of adiponectin in patients with coronary artery disease, Heart 90(5) (2004), 528-533.

[52] S.J. Hong, H.S. Seo, S.W. Rha et al., Decrease in plasma adiponectin concentrations in patients with variant angina pectoris, Circ J 70(4) (2006), 414-418.

[53] S. Pilz, W. Maerz, G. Weihrauch et al., Adiponectin serum concentrations in men with coronary artery disease: the LUdwigshafen RIsk and Cardiovascular Health (LURIC) study, Clin Chim Acta 364(1-2) (2006), 251-255.

[54] M. von Eynatten, J.G. Schneider, P.M. Humpert et al., Serum adiponectin levels are an independent predictor of the extent of coronary artery disease in men, $\mathrm{J} \mathrm{Am}$ Coll Cardiol 47(10) (2006), 2124-2126.

[55] F. Otsuka, S. Sugiyama, S. Kojima et al., Plasma adiponectin levels are associated with coronary lesion complexity in men with coronary artery disease, J Am Coll Cardiol 48(6) (2006), 1155-1162.

[56] P.E. Szmitko, H. Teoh, D.J. Stewart and S. Verma, Adiponectin and cardiovascular disease: state of the art? Am J Physiol Heart Circ Physiol 292(4) (2007), H1655-H1663.

[57] T. Pischon, Adiponectin: a biomarker of obesity? Current Cardiovascular Risk Reports 2 (2008), 150-155.

[58] T. Pischon, C.J. Girman, G.S. Hotamisligil, N. Rifai, F.B. $\mathrm{Hu}$ and E.B. Rimm, Plasma adiponectin levels and risk of myocardial infarction in men, Jama 291(14) (2004), 17301737.

[59] M.B. Schulze, I. Shai, E.B. Rimm, T. Li, N. Rifai and F.B. Hu, Adiponectin and future coronary heart disease events among men with type 2 diabetes, Diabetes 54(2) (2005), 534-539.

[60] D.M. Maahs, L.G. Ogden, G.L. Kinney et al., Low plasma adiponectin levels predict progression of coronary artery calcification, Circulation 111(6) (2005), 747-753.
[61] J. Frystyk, C. Berne, L. Berglund, K. Jensevik, A. Flyvbjerg and B. Zethelius, Serum adiponectin is a predictor of coronary heart disease: a population-based 10-year follow-up study in elderly men, J Clin Endocrinol Metab 92(2) (2007), 571-576.

[62] R.S. Lindsay, H.E. Resnick, J. Zhu et al., Adiponectin and coronary heart disease: the Strong Heart Study, Arterioscler Thromb Vasc Biol 25(3) (2005), e15-e16.

[63] D.A. Lawlor, G. Davey Smith, S. Ebrahim, C. Thompson and N. Sattar, Plasma adiponectin levels are associated with insulin resistance, but do not predict future risk of coronary heart disease in women, J Clin Endocrinol Metab 90(10) (2005), 5677-5683.

[64] N. Sattar, G. Wannamethee, N. Sarwar et al., Adiponectin and coronary heart disease: a prospective study and metaanalysis, Circulation 114(7) (2006), 623-629.

[65] W. Koenig, N. Khuseyinova, J. Baumert, C. Meisinger and H. Lowel, Serum concentrations of adiponectin and risk of type 2 diabetes mellitus and coronary heart disease in apparently healthy middle-aged men: results from the 18-year follow-up of a large cohort from southern Germany, J Am Coll Cardiol 48(7) (2006), 1369-1377.

[66] S. Soderberg, B. Stegmayr, H. Stenlund et al., Leptin, but not adiponectin, predicts stroke in males, $J$ Intern Med 256(2) (2004), 128-136.

[67] M. Matsumoto, S. Ishikawa and E. Kajii, Association of adiponectin with cerebrovascular disease: a nested casecontrol study, Stroke 39(2) (2008), 323-328.

[68] E. Ingelsson, U. Riserus, C. Berne et al., Adiponectin and risk of congestive heart failure, Jama 295(15) (2006), 17721774.

[69] C. Kistorp, J. Faber, S. Galatius et al., Plasma adiponectin, body mass index, and mortality in patients with chronic heart failure, Circulation 112(12) (2005), 1756-1762.

[70] J. George, S. Patal, D. Wexler et al., Circulating adiponectin concentrations in patients with congestive heart failure, Heart 92(10) (2006), 1420-1424.

[71] T. Tamura, Y. Furukawa, R. Taniguchi et al., Serum adiponectin level as an independent predictor of mortality in patients with congestive heart failure, Circ J 71(5) (2007), 623-630.

[72] T. Tsutamoto, T. Tanaka, H. Sakai et al., Total and high molecular weight adiponectin, haemodynamics, and mortality in patients with chronic heart failure, Eur Heart $J$ 28(14) (2007), 1723-1730.

[73] S.G. Wannamethee, P.H. Whincup, L. Lennon and N. Sattar, Circulating adiponectin levels and mortality in elderly men with and without cardiovascular disease and heart failure, Arch Intern Med 167(14) (2007), 1510-1517.

[74] G.A. Laughlin, E. Barrett-Connor, S. May and C. Langenberg, Association of adiponectin with coronary heart disease and mortality: the Rancho Bernardo study, Am J Epidemiol 165(2) (2007), 164-174.

[75] J.M. Dekker, T. Funahashi, G. Nijpels et al., Prognostic value of adiponectin for cardiovascular disease and mortality, $J$ Clin Endocrinol Metab (2008).

[76] I. Kelesidis, T. Kelesidis and C.S. Mantzoros, Adiponectin and cancer: a systematic review, Br J Cancer 94(9) (2006), 1221-1215.

[77] M.B. McEntegart, B. Awede, M.C. Petrie et al., Increase in serum adiponectin concentration in patients with heart failure and cachexia: relationship with leptin, other cytokines, and B-type natriuretic peptide, Eur Heart J 28(7) (2007), 829835. 
[78] W. Rathmann and C. Herder, Adiponectin and cardiovascular mortality: evidence for "reverse epidemiology", Horm Metab Res 39(1) (2007), 1-2.

[79] J.P. Curtis, J.G. Selter, Y. Wang et al., The obesity paradox: body mass index and outcomes in patients with heart failure, Arch Intern Med 165(1) (2005), 55-61.

[80] K. Kalantar-Zadeh, G. Block, T. Horwich and G.C. Fonarow, Reverse epidemiology of conventional cardiovascular risk factors in patients with chronic heart failure, J Am Coll Cardiol 43(8) (2004), 1439-1444

[81] K.F. Adams, A. Schatzkin, T.B. Harris et al., Overweight, obesity, and mortality in a large prospective cohort of persons 50 to 71 years old, N Engl J Med 355(8) (2006), 763-778.

[82] C. Heidemann, Q. Sun, R.M. van Dam et al., Total and highmolecular-weight adiponectin and resistin in relation to the risk for type 2 diabetes in women, Ann Intern Med 149(5) (2008), 307-316.

[83] N. Sattar, P. Watt, L. Cherry, S. Ebrahim, G. Davey Smith and D.A. Lawlor, High molecular weight adiponectin is not associated with incident coronary heart disease in older women: a nested prospective case-control study, J Clin Endocrinol Metab 93(5) (2008), 1846-1849.

[84] Y. Takemura, N. Ouchi, R. Shibata et al., Adiponectin modulates inflammatory reactions via calreticulin receptordependent clearance of early apoptotic bodies, J Clin Invest 117(2) (2007), 375-386.

[85] C.M. Steppan, S.T. Bailey, S. Bhat et al., The hormone resistin links obesity to diabetes, Nature 409(6818) (2001), 307-312.

[86] C.M. Steppan, E.J. Brown, C.M. Wright et al., A family of tissue-specific resistin-like molecules, Proc Natl Acad Sci U $S$ A 98(2) (2001), 502-506.

[87] J.M. Way, C.Z. Gorgun, Q. Tong et al., Adipose tissue resistin expression is severely suppressed in obesity and stimulated by peroxisome proliferator-activated receptor gamma agonists, J Biol Chem 276(28) (2001), 25651-25653.

[88] H. Fujita, H. Fujishima, T. Morii et al., Effect of metformin on adipose tissue resistin expression in $\mathrm{db} / \mathrm{db}$ mice, Biochem Biophys Res Commun 298(3) (2002), 345-349.

[89] Y. Fukui and K. Motojima, Expression of resistin in the adipose tissue is modulated by various factors including peroxisome proliferator-activated receptor alpha, Diabetes Obes Metab 4(5) (2002), 342-345.

[90] M.W. Rajala, S. Obici, P.E. Scherer and L. Rossetti, Adiposederived resistin and gut-derived resistin-like molecule-beta selectively impair insulin action on glucose production, $J$ Clin Invest 111(2) (2003), 225-230.

[91] D.B. Savage, C.P. Sewter, E.S. Klenk et al., Resistin / Fizz3 expression in relation to obesity and peroxisome proliferatoractivated receptor-gamma action in humans, Diabetes $\mathbf{5 0}(10)$ (2001), 2199-2202.

[92] I. Nagaev and U. Smith, Insulin resistance and type 2 diabetes are not related to resistin expression in human fat cells or skeletal muscle, Biochem Biophys Res Commun 285(2) (2001), 561-564.

[93] J. Janke, S. Engeli, K. Gorzelniak, F.C. Luft and A.M. Sharma, Resistin gene expression in human adipocytes is not related to insulin resistance, Obes Res 10(1) (2002), 1-5.

[94] M. Degawa-Yamauchi, J.E. Bovenkerk, B.E. Juliar et al, Serum resistin (FIZZ3) protein is increased in obese humans, J Clin Endocrinol Metab 88(11) (2003), 5452-5455.

[95] K. Azuma, F. Katsukawa, S. Oguchi et al., Correlation between serum resistin level and adiposity in obese individuals, Obes Res 11(8) (2003), 997-1001.
[96] A. Fujinami, H. Obayashi, K. Ohta et al., Enzyme-linked immunosorbent assay for circulating human resistin: resistin concentrations in normal subjects and patients with type 2 diabetes, Clin Chim Acta 339(1-2) (2004), 57-63.

[97] J.H. Lee, J.L. Chan, N. Yiannakouris et al., Circulating resistin levels are not associated with obesity or insulin resistance in humans and are not regulated by fasting or leptin administration: cross-sectional and interventional studies in normal, insulin-resistant, and diabetic subjects, J Clin Endocrinol Metab 88(10) (2003), 4848-4856.

[98] A. Pfutzner, M. Langenfeld, T. Kunt, M. Lobig and T. Forst, Evaluation of human resistin assays with serum from patients with type 2 diabetes and different degrees of insulin resistance, Clin Lab 49(11-12) (2003), 571-576.

[99] I.N. Holcomb, R.C. Kabakoff, B. Chan et al., FIZZ1, a novel cysteine-rich secreted protein associated with pulmonary inflammation, defines a new gene family, Embo $J$ 19(15) (2000), 4046-4055.

[100] J. Gomez-Ambrosi and G. Fruhbeck, Do resistin and resistinlike molecules also link obesity to inflammatory diseases? Ann Intern Med 135(4) (2001), 306-307.

[101] S. Verma, S.H. Li, C.H. Wang et al., Resistin promotes endothelial cell activation: further evidence of adipokineendothelial interaction, Circulation 108(6) (2003), 736-740.

[102] D. Kawanami, K. Maemura, N. Takeda et al., Direct reciprocal effects of resistin and adiponectin on vascular endothelial cells: a new insight into adipocytokine-endothelial cell interactions, Biochem Biophys Res Commun 314(2) (2004), 415-419.

[103] R. Ohmori, Y. Momiyama, R. Kato et al., Associations between serum resistin levels and insulin resistance, inflammation, and coronary artery disease, J Am Coll Cardiol 46(2) (2005), 379-380.

[104] T. Pischon, C.M. Bamberger, J. Kratzsch et al., Association of plasma resistin levels with coronary heart disease in women, Obes Res 13(10) (2005), 1764-1771.

[105] M.P. Reilly, M. Lehrke, M.L. Wolfe, A. Rohatgi, M.A. Lazar and D.J. Rader, Resistin is an inflammatory marker of atherosclerosis in humans, Circulation 111(7) (2005), 932939.

[106] C. Weikert, S. Westphal, K. Berger et al., Plasma resistin levels and risk of myocardial infarction and ischemic stroke, J Clin Endocrinol Metab 93(7) (2008), 2647-2653.

[107] C. Weikert, K. Berger, C. Heidemann et al., Joint effects of risk factors for stroke and transient ischemic attack in a German population: the EPIC Potsdam Study, J Neurol 254(3) (2007), 315-321.

[108] H.R. Yusuf, W.H. Giles, J.B. Croft, R.F. Anda and M.L. Casper, Impact of multiple risk factor profiles on determining cardiovascular disease risk, Prev Med 27(1) (1998), 1-9.

[109] A. Patel, M. Woodward, D.J. Campbell et al., Plasma lipids predict myocardial infarction, but not stroke, in patients with established cerebrovascular disease, Eur Heart J 26(18) (2005), 1910-1915.

[110] A. Kunnari, O. Ukkola, M. Paivansalo and Y.A. Kesaniemi, High plasma resistin level is associated with enhanced highly sensitive C-reactive protein and leukocytes, J Clin Endocrinol Metab 91(7) (2006), 2755-2760.

[111] R.P. Dullaart, R. de Vries, A. van Tol and W.J. Sluiter, Lower plasma adiponectin is a marker of increased intima-media thickness associated with type 2 diabetes mellitus and with male gender, Eur J Endocrinol 156(3) (2007), 387-394.

[112] G.D. Norata, M. Ongari, K. Garlaschelli, S. Raselli, L. Grigore and A.L. Catapano, Plasma resistin levels correlate with 
determinants of the metabolic syndrome, Eur J Endocrinol 156(2) (2007), 279-284.

[113] B. Seese, M. Brandt-Pohlmann, W. Moshage, S. Achenbach, T. Schwarz and K. Bachmann, Evaluation of the Association Between Coronary Calcification Detected by Electron Beam Computed Tomography and Atherosclerosis of Extracranial Carotid Arteries In Vivo, Int J Angiol 7(4) (1998), 301-306.

[114] N. Stefan, A.M. Hennige, H. Staiger et al., Alpha2Heremans-Schmid glycoprotein/fetuin-A is associated with insulin resistance and fat accumulation in the liver in humans, Diabetes Care 29(4) (2006), 853-857.

[115] P. Angulo, Nonalcoholic fatty liver disease, N Engl J Med 346(16) (2002), 1221-1231.

[116] G. Targher and G. Arcaro, Non-alcoholic fatty liver disease and increased risk of cardiovascular disease, Atherosclerosis 191(2) (2007), 235-240.

[117] G. Targher, L. Bertolini, R. Padovani, L. Zenari, G. Zoppini and G. Falezza, Relation of nonalcoholic hepatic steatosis to early carotid atherosclerosis in healthy men: role of visceral fat accumulation, Diabetes Care 27(10) (2004), 2498-2500.

[118] U. Arslan, S. Turkoglu, S. Balcioglu, Y. Tavil, T. Karakan and A. Cengel, Association between nonalcoholic fatty liver disease and coronary artery disease, Coron Artery Dis 18(6) (2007), 433-436.

[119] B. Denecke, S. Graber, C. Schafer, A. Heiss, M. Woltje and W. Jahnen-Dechent, Tissue distribution and activity testing suggest a similar but not identical function of fetuin-B and fetuin-A, Biochem J 376(Pt 1) (2003), 135-145.

[120] P. Auberger, L. Falquerho, J.O. Contreres et al., Characterization of a natural inhibitor of the insulin receptor tyrosine kinase: cDNA cloning, purification, and anti-mitogenic activity, Cell 58(4) (1989), 631-640.

[121] G. Rauth, O. Poschke, E. Fink et al., The nucleotide and partial amino acid sequences of rat fetuin. Identity with the natural tyrosine kinase inhibitor of the rat insulin receptor, Eur J Biochem 204(2) (1992), 523-529.

[122] S.T. Mathews, G.P. Singh, M. Ranalletta et al., Improved insulin sensitivity and resistance to weight gain in mice null for the Ahsg gene, Diabetes 51(8) (2002), 2450-2458.

[123] K. Mori, M. Emoto, H. Yokoyama et al., Association of serum fetuin-A with insulin resistance in type 2 diabetic and nondiabetic subjects, Diabetes Care 29(2) (2006), 468.

[124] J.H. Ix, M.G. Shlipak, V.M. Brandenburg, S. Ali, M. Ketteler and M.A. Whooley, Association between human fetuin-A and the metabolic syndrome: data from the Heart and Soul Study, Circulation 113(14) (2006), 1760-1767.

[125] J.H. Ix, C.L. Wassel, A.M. Kanaya et al., Fetuin-A and incident diabetes mellitus in older persons, Jama 300(2) (2008), 182-188.

[126] N. Stefan, A. Fritsche, C. Weikert et al., Plasma fetuin-A levels and the risk of type 2 diabetes, Diabetes 57(10) (2008), 2762-2767.

[127] A.M. Hennige, H. Staiger, C. Wicke et al., Fetuin-A induces cytokine expression and suppresses adiponectin production, PLOS ONE 3(3) (2008), e1765.

[128] C. Weikert, N. Stefan, M.B. Schulze et al., Plasma Fetuin-A Levels and the Risk of Myocardial Infarction and Ischemic Stroke, Circulation 2008.

[129] R. Mehrotra, Emerging role for fetuin-A as contributor to morbidity and mortality in chronic kidney disease, Kidney Int 72(2) (2007), 137-140.

[130] M. Ciaccio, G. Bivona, R. Di Sciacca et al., Changes in serum fetuin-A and inflammatory markers levels in end-stage renal disease (ESRD): effect of a single session haemodialysis, Clin Chem Lab Med 46(2) (2008), 212-214.

[131] M. Szweras, D. Liu, E.A. Partridge et al., alpha 2-HS glycoprotein/fetuin, a transforming growth factor-beta/bone morphogenetic protein antagonist, regulates postnatal bone growth and remodeling, J Biol Chem 277(22) (2002), 1999119997.

[132] J.J. Kaden, J.O. Reinohl, B. Blesch et al., Systemic and local levels of fetuin-A in calcific aortic valve stenosis, Int J Mol Med 20(2) (2007), 193-197.

[133] J.H. Ix, G.M. Chertow, M.G. Shlipak, V.M. Brandenburg, M. Ketteler and M.A. Whooley, Association of fetuin-A with mitral annular calcification and aortic stenosis among persons with coronary heart disease: data from the Heart and Soul Study, Circulation 115(19) (2007), 2533-2539.

[134] R. Mehrotra, R. Westenfeld, P. Christenson et al., Serum fetuin-A in nondialyzed patients with diabetic nephropathy: relationship with coronary artery calcification, Kidney Int 67(3) (2005), 1070-1077.

[135] J.H. Ix, M.G. Shlipak, M.J. Sarnak et al., Fetuin-A is not associated with mortality in chronic kidney disease, Kidney Int 72(11) (2007), 1394-1399.

[136] D.L. Streiner and G.R. Norman, "Precision" and "accuracy": two terms that are neither, J Clin Epidemiol 59(4) (2006), 327-330.

[137] J.L. Fleiss, Reliability of measurement, in: The Design and Analysis of Clinical Experiments, J.L. Fleiss, ed., New York: Wiley and Sons, 1986, PP. 1-32.

[138] Expert Panel on the Identification E, and Treatment of Overweight and Obesity in Adults, Clinical guidelines on the identification, evaluation, and treatment of overweight and obesity in adults - the evidence report - NIH PUBLICATION NO. 98-4083. Bethesda: National Institutes of Health, 1998.

[139] M. Krotkiewski, P. Bjorntorp, L. Sjostrom and U. Smith, Impact of obesity on metabolism in men and women. Importance of regional adipose tissue distribution, J Clin Invest 72(3) (1983), 1150-1162.

[140] C. Menzaghi, V. Trischitta and A. Doria, Genetic influences of adiponectin on insulin resistance, type 2 diabetes, and cardiovascular disease, Diabetes 56(5) (2007), 1198-1209.

[141] F.G. Hage and A.J. Szalai, C-reactive protein gene polymorphisms, C-reactive protein blood levels, and cardiovascular disease risk, J Am Coll Cardiol 50(12) (2007), 1115-1122.

[142] I.M. Heid, S.A. Wagner, H. Gohlke et al., Genetic architecture of the APM1 gene and its influence on adiponectin plasma levels and parameters of the metabolic syndrome in 1,727 healthy Caucasians, Diabetes 55(2) (2006), 375-384.

[143] T. Pischon, J.K. Pai, J.E. Manson et al., Single nucleotide polymorphisms at the adiponectin locus and risk of coronary heart disease in men and women, Obesity (Silver Spring) 15(8) (2007), 2051-2060.

[144] M.F. Hivert, A.K. Manning, J.B. McAteer et al., Association of Variants in RETN with Plasma Resistin Levels and Diabetes-Related Traits in the Framingham Offspring Study, Diabetes 2008.

[145] L. Qi, R.M. van Dam, J.B. Meigs, J.E. Manson, D. Hunter and F.B. $\mathrm{Hu}$, Genetic variation in IL6 gene and type 2 diabetes: tagging-SNP haplotype analysis in large-scale case-control study and meta-analysis, Hum Mol Genet 15(11) (2006), 1914-1920.

[146] T. Rankinen, A. Zuberi, Y.C. Chagnon et al., The human obesity gene map: the 2005 update, Obesity (Silver Spring) 14(4) (2006), 529-644. 
[147] T.M. Frayling, N.J. Timpson, M.N. Weedon et al., A common variant in the FTO gene is associated with body mass index and predisposes to childhood and adult obesity, Science 316(5826) (2007), 889-894.

[148] L.J. Scott, K.L. Mohlke, L.L. Bonnycastle et al., A genomewide association study of type 2 diabetes in Finns detects multiple susceptibility variants, Science 316(5829) (2007), 1341-1345.

[149] C. Dina, D. Meyre, S. Gallina et al., Variation in FTO contributes to childhood obesity and severe adult obesity, Nat Genet 39(6) (2007), 724-726.

[150] E. Fisher, M.B. Schulze, N. Stefan et al., Association of the FTO rs9939609 Single Nucleotide Polymorphism With C-reactive Protein Levels, Obesity (Silver Spring) 2008.

[151] K. Prasad, C-reactive protein (CRP)-lowering agents, Cardiovasc Drug Rev 24(1) (2006), 33-50.

[152] F.B. Hu, J.E. Manson and W.C. Willett, Types of dietary fat and risk of coronary heart disease: a critical review, $J$ Am Coll Nutr 20(1) (2001), 5-19.

[153] W.E. Connor, Importance of $n-3$ fatty acids in health and disease, Am J Clin Nutr 71(1 Suppl) (2000), 171S-175S.

[154] A.P. Simopoulos, A. Leaf and N. Salem, Jr., Workshop statement on the essentiality of and recommended dietary intakes for Omega-6 and Omega-3 fatty acids, Prostaglandins Leukot Essent Fatty Acids 63(3) (2000), 119-121.

[155] T. Pischon, S.E. Hankinson, G.S. Hotamisligil, N. Rifai, W.C. Willett and E.B. Rimm, Habitual dietary intake of $n-3$ and $n-6$ fatty acids in relation to inflammatory markers among US men and women, Circulation 108(2) (2003), 155-160.

[156] D. Mozaffarian, T. Pischon, S.E. Hankinson et al., Dietary intake of trans fatty acids and systemic inflammation in women, Am J Clin Nutr 79(4) (2004), 606-612.

[157] E.B. Rimm, E.L. Giovannucci, W.C. Willett et al., Prospective study of alcohol consumption and risk of coronary disease in men, Lancet 338(8765) (1991), 464-468.

[158] R.D. Langer, M.H. Criqui and D.M. Reed, Lipoproteins and blood pressure as biological pathways for effect of moderate alcohol consumption on coronary heart disease, Circulation 85(3) (1992), 910-915.

[159] K.J. Mukamal, M.K. Jensen, M. Gronbaek et al., Drinking frequency, mediating biomarkers, and risk of myocardial infarction in women and men, Circulation 112(10) (2005), 1406-1413.

[160] J.K. Pai, S.E. Hankinson, R. Thadhani, N. Rifai, T. Pischon and E.B. Rimm, Moderate alcohol consumption and lower levels of inflammatory markers in US men and women, Atherosclerosis 186(1) (2006), 113-120.

[161] A. Imhof, M. Froehlich, H. Brenner, H. Boeing, M.B. Pepys and W. Koenig, Effect of alcohol consumption on systemic markers of inflammation, Lancet 357(9258) (2001), 763767.

[162] M.A. Albert, R.J. Glynn and P.M. Ridker, Alcohol consumption and plasma concentration of C-reactive protein, $\mathrm{Circu}$ lation 107(3) (2003), 443-447.

[163] T. Pischon, C.J. Girman, N. Rifai, G.S. Hotamisligil and E.B. Rimm, Association between dietary factors and plasma adiponectin concentrations in men, Am J Clin Nutr 81(4) (2005), 780-786

[164] C. Thamer, M. Haap, A. Fritsche, H. Haering and M. Stumvoll, Relationship between moderate alcohol consumption and adiponectin and insulin sensitivity in a large heterogeneous population, Diabetes Care 27(5) (2004), 1240.

[165] A. Avogaro, M. Sambataro, A. Marangoni et al., Moderate alcohol consumption, glucose metabolism and lipolysis: the effect on adiponectin and tumor necrosis factor alpha, $J$ Endocrinol Invest 26(12) (2003), 1213-1218.

[166] J.R. Greenfield, K. Samaras, C.S. Hayward, D.J. Chisholm and L.V. Campbell, Beneficial postprandial effect of a small amount of alcohol on diabetes and cardiovascular risk factors: modification by insulin resistance, J Clin Endocrinol Metab 90(2) (2005), 661-672.

[167] A. Sierksma, M.S. van der Gaag, C. Kluft and H.F. Hendriks, Moderate alcohol consumption reduces plasma C-reactive protein and fibrinogen levels; a randomized, diet-controlled intervention study, Eur J Clin Nutr 56(11) (2002), 11301136.

[168] A. Sierksma, H. Patel, N. Ouchi et al., Effect of moderate alcohol consumption on adiponectin, tumor necrosis factoralpha, and insulin sensitivity, Diabetes Care 27(1) (2004), 184-189.

[169] J.W. Beulens, R.M. van Beers, R.P. Stolk, G. Schaafsma and H.F. Hendriks, The effect of moderate alcohol consumption on fat distribution and adipocytokines, Obesity (Silver Spring) 14(1) (2006), 60-66.

[170] S. Liu, J.E. Manson, J.E. Buring, M.J. Stampfer, W.C. Willett and E.M. Ridker, Relation between a diet with a high glycemic load and plasma concentrations of high-sensitivity C-reactive protein in middle-aged women, Am J Clin Nutr 75(3) (2002), 492-498.

[171] S. Liu, W.C. Willett, M.J. Stampfer et al., A prospective study of dietary glycemic load, carbohydrate intake, and risk of coronary heart disease in US women, Am J Clin Nutr 71(6) (2000), 1455-1461.

[172] P.D. Thompson, D. Buchner, I.L. Pina et al., Exercise and physical activity in the prevention and treatment of atherosclerotic cardiovascular disease: a statement from the Council on Clinical Cardiology (Subcommittee on Exercise, Rehabilitation, and Prevention) and the Council on Nutrition, Physical Activity, and Metabolism (Subcommittee on Physical Activity), Circulation 107(24) (2003), 3109-3116.

[173] S.G. Wannamethee, G.D. Lowe, P.H. Whincup, A. Rumley, M. Walker and L. Lennon, Physical activity and hemostatic and inflammatory variables in elderly men, Circulation 105(15) (2002), 1785-1790.

[174] K. Esposito, A. Pontillo, C. Di Palo et al., Effect of weight loss and lifestyle changes on vascular inflammatory markers in obese women: a randomized trial, Jama 289(14) (2003), 1799-1804.

[175] T. Pischon, S.E. Hankinson, G.S. Hotamisligil, N. Rifai and E.B. Rimm, Leisure-Time Physical Activity and Reduced Plasma Levels of Obesity-Related Inflammatory Markers, Obes Res 11(9) (2003), 1055-1064.

[176] J.L. Abramson and V. Vaccarino, Relationship between physical activity and inflammation among apparently healthy middle-aged and older US adults, Arch Intern Med 162(11) (2002), 1286-1292.

[177] R.M. Robertson and L. Smaha. Can a Mediterranean-style diet reduce heart disease? Circulation 103(13) (2001), 18211822.

[178] N.R. Cook, Use and misuse of the receiver operating characteristic curve in risk prediction, Circulation 115(7) (2007), 928-935.

[179] J.A. Hanley and B.J. McNeil, The meaning and use of the area under a receiver operating characteristic (ROC) curve, Radiology 143(1) (1982), 29-36.

[180] US Department of Health and Human Services. A Public Health Action Plan to Prevent Heart Disease and Stroke. 
Atlanta, GA: US Department of Health and Human Services, Centers for Disease Control and Prevention, 2003.

[181] P.A. Schulte, A conceptual and historical framework for molecular epidemiology, in: Molecular Epidemiology: Principles and Practices, P.A. Schulte and F.P. Perera, eds, San Diego: Academic Press, 1993, PP. 3-44.

[182] T. Pischon, G.S. Hotamisligil and E.B. Rimm, Adiponectin:
Stability in Plasma over 36 Hours and Within-Person Variation over 1 Year, Clin Chem 49(4) (2003), 650-652.

[183] C. Weikert, S. Westphal, C. Luley, S.N. Willich, H. Boeing and T. Pischon, Within-subject variation of plasma resistin levels over a 1-year period, Clin Chem Lab Med 45(7) (2007), 899-902. 


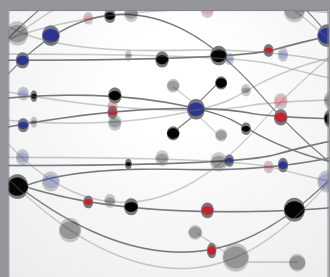

The Scientific World Journal
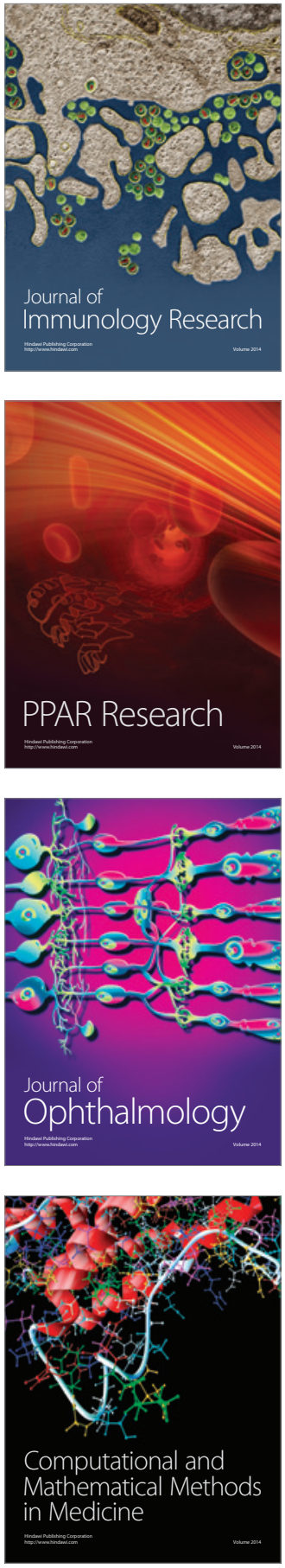

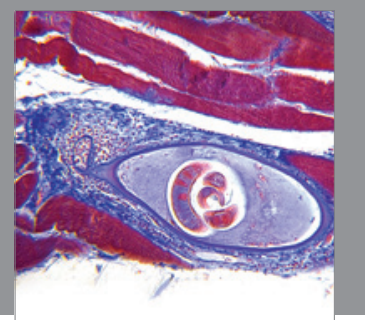

Gastroenterology

Research and Practice
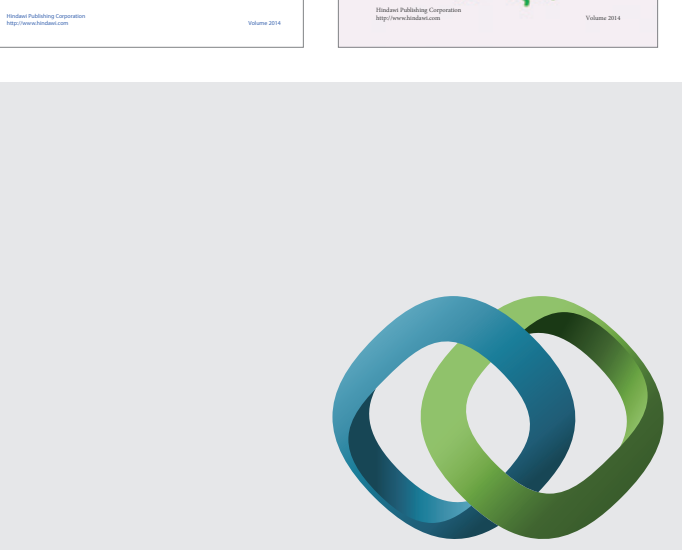

\section{Hindawi}

Submit your manuscripts at

http://www.hindawi.com
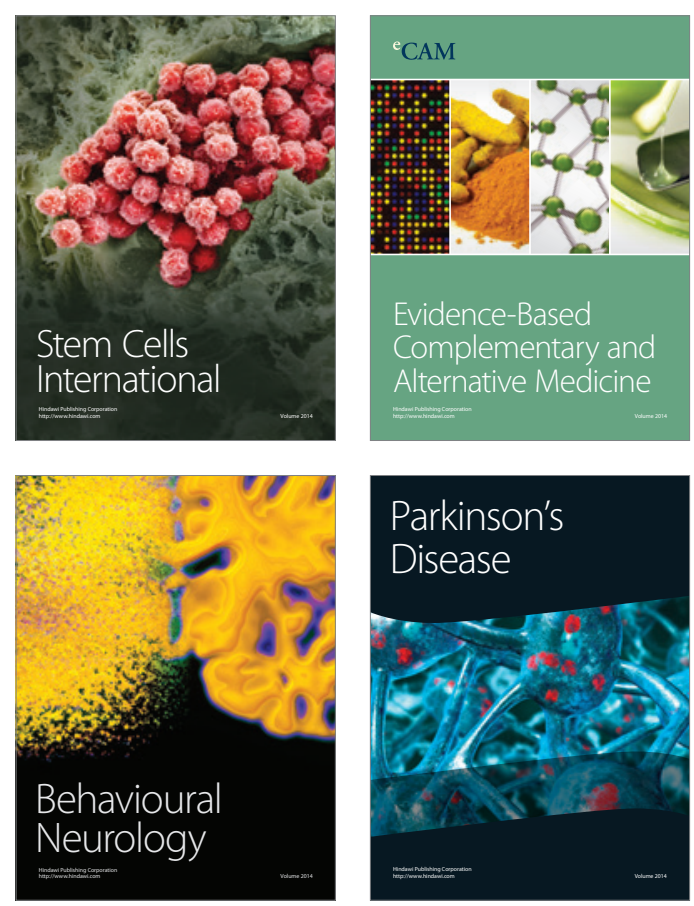

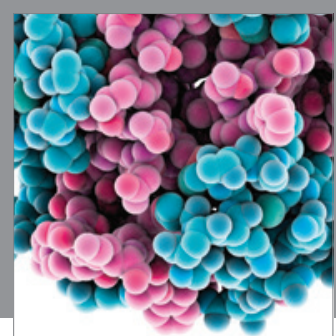

Journal of
Diabetes Research

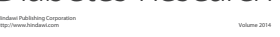

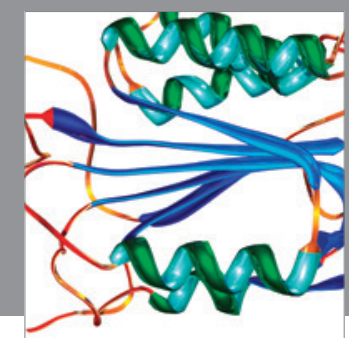

Disease Markers
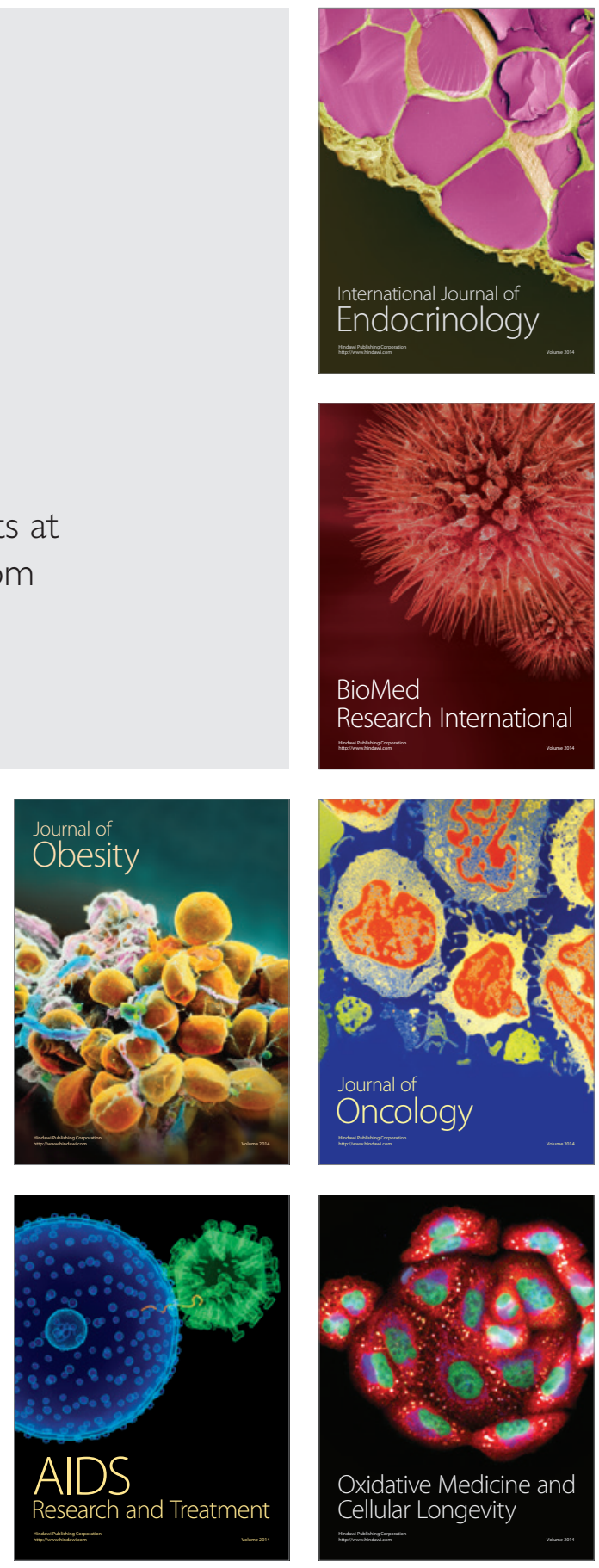